\title{
Acting Front to Nursing Psychological Repercussions in Breast Cancer Patients
}

\author{
Maria do Socorro Santos de Oliveira' ${ }^{1}$, Adalberto Cruz Sampaio², Camila Macêdo de Figueiredo, \\ Silva Morais de Santana Ferreira3 ${ }^{3}$, Natália Moreira Garcia Feitosa4, \\ Rosângela Rodrigues dos Santos ${ }^{5}$, Petrúcya Frazão Lira1, Milana Drumond Ramos Santana1
}

${ }^{1}$ College of Juazeiro do Norte, Juazeiro do Norte, CE, Brazil

${ }^{2}$ University Center Leão Sampaio, Juazeiro do Norte, CE, Brazil

${ }^{3}$ Retired, Juazeiro do Norte, CE, Brazil

${ }^{4}$ Maternity Hospital São Vicente, College of Medicine, Juazeiro do Norte, CE, Brazil

${ }^{5}$ Center for Attention to Student (NAE), College of Juazeiro do Norte, Juazeiro do Norte, CE, Brazil

Email: maria.mariadosocorro.santos@hotmail.com

How to cite this paper: Oliveira, M.S.S., Sampaio, A.C., Figueiredo, C.M., Ferreira, S.M.S., Feitosa, N.M.G., Santos, R.R., Lira, P.F. and Santana, M.D.R. (2016) Acting Front to Nursing Psychological Repercussions in Breast Cancer Patients. Open Journal of Nursing, 6, 987-994.

http://dx.doi.org/10.4236/ojn.2016.612095

Received: November 9, 2016

Accepted: December 2, 2016

Published: December 5, 2016

Copyright $\odot 2016$ by authors and Scientific Research Publishing Inc. This work is licensed under the Creative Commons Attribution International License (CC BY 4.0).

http://creativecommons.org/licenses/by/4.0/

\begin{abstract}
Breast cancer is a heterogeneous and complex disease with different situations of threat to their patients, which can cause psychological discomfort, anxiety and a depressed state in women. The aim of this study was to analyze the performance of nursing to psychological repercussions on living with breast cancer. This is a descriptive and cross-sectional study with qualitative characteristics. It was conducted with professional nurses in Basic Health Units (UBS) in the municipality of Juazeiro do Norte-CE, Northeast of Brazil, located in the region of Cariri. The study began to be developed after the approval of the Research Ethics Committee, CAAE: 50809315.8. 0000.5624. Data collection occurred through a semi-structured interview. For the interpretation of the results, the technique of content analysis was used. The results showed that nurses realize that emotional support, care and assistance in coping, improve the construction of a good performance of the professional nurse. However, it is possible to realize the need for information and qualified assistance by multidisciplinary team to these patients and even their family members. It was identified as difficulty in assisting the denial of patient to start the treatment, but the facility is in the intimacy that the professional nurse can engage with the customer. It highlighted the care through dialogue and health education. And, finally, the nurse is aware of such importance of his/her role when supporting the patient. Thus, the improvement of professional assistance was evidenced as regards emotional support, reception, qualified listening, health education measures leading to self-knowledge, self-esteem and acceptance of the disease and the creation of bonds with the patients.
\end{abstract}




\title{
Keywords
}

\author{
Nursing Care, Breast Cancer, Women's Health
}

\section{Introduction}

Breast cancer is the second most common type of cancer in the world population and it is the most common among women, being one of the leading causes of death among them [1]. The National Cancer Institute (INCA) [2] confirms the heterogeneity of this pathology by its distinct behavior, being observed by the varied clinical manifestations, different genetic signatures and consequent differences in therapeutic responses.

Estimates for the year 2015 in Brazil amounted to 57,120 new cases (gross rate of incidence of 56.09 per 100,000 women). In 2013, there were 14,206 deaths by this cause (gross rate of mortality of 14.35 deaths per 100,000 women), being the average of the mortality gross rate for the period from 2009 to 2013 of 13.38 deaths per 100,000 women [3].

However, area scholars point out that the treatment of breast cancer, the surgery, radiotherapy and chemotherapy are the most therapeutic modalities used in its treatment. According to several national studies, all of them can entail important psychological repercussions, since the disease affects an organ that symbolizes femininity, sensuality, sexuality and motherhood [4].

Carvalho et al. [1] claim that the diagnosis of cancer is usually an emotional overload which can trigger reactions and emotional adjustment or even be the trigger for affective disorders (especially depression), anxiety or even psychological disorders. However, it is important to note that not all mood swings can be considered depression. Often, the patient has only emotional lability or mood light changes.

In this way, patient's emotional care is the responsibility of all health team, which needs to be in emotional conditions to work with patients, their families and the community [1].

The National Cancer Institute recognizes the role of the nurse in the multidisciplinary team in saying that his/her activities must pervade all support steps, so that it begins immediately after the diagnosis of the disease and accompanies the woman after the moment of medical discharge until her reinstatement to everyday life [5].

Therefore, it is expected that the nurse, faced with the problem, realizes the need of providing care not only theoretical-practical and technical, but with a specific perception of the problem of his patients, positioning and facing along with the patient and her family the diagnosis and treatment that will be done, since the family members, as much as the patient, are not ready to receive the diagnosis.

However, understanding, studying and knowing the breast cancer that affects these women and the effects generated in their lives become important not only for knowledge as a nursing professional, but also for a more effectively performance in caring 
patients with breast cancer.

Thus, the aim of this study was to analyze the performance of nursing to psychological repercussions on living with breast cancer.

\section{Method}

This is a descriptive and cross-sectional study with qualitative characteristics. It was conducted with professional nurses in Basic Health Units (UBS) in the municipality of Juazeiro do Norte-CE, Northeast of Brazil, located in the region of Cariri, with a population of 266,022 inhabitants (IBGE, 2015). The study began to be developed after the approval of the Research Ethics Committee, CAAE: 50809315.8.0000.5624.

Nurses of the UBS were invited to participate in the study, in the said municipality. These were defined as inclusion criteria: being nurse in the Basic Health Unit with a minimum of six months of work, having specialization in Family Health or other specialization in the nursing area, and having already attended a patient with breast cancer at the Basic Health Unit.

A semi-structured interview was used as an instrument of data collection. The interview addressed specific questions to nurses on nursing activities in the psychological consequences of breast cancer patients. For the interpretation of the results, the technique of content analysis was used.

The research was held in accordance with the ethical and legal aspects of 466/12 Resolution. This Resolution includes, from the perspective of the individual and the communities, the four basic references of bioethics: autonomy; non maleficence; beneficence and justice, among others; and it aims to ensure the rights and duties concerning the scientific community, the research subjects and the State (BRAZIL, 2012).

\section{Results and Discussion}

Table 1 shows the sociodemographic characteristics of the research participants.

The following discusses nurses' practices on nursing performance regarding the psychological repercussions on breast cancer patients in UBS, based on testimonies of nurses, in which all were named with names relating from Enf1 to Enf10.

\section{Categorization of Speech}

After organizing the speeches, the following categories emerged, as the proposed objec-

Table 1. Sociodemographic characteristics.

\begin{tabular}{ccccc}
\hline $\begin{array}{c}\text { Age group of } \\
\text { the participants }\end{array}$ & $\begin{array}{c}\text { Female } \\
\text { participants }\end{array}$ & $\begin{array}{c}\text { Male } \\
\text { participants }\end{array}$ & $\begin{array}{c}\text { Graduation time } \\
\text { of the interviewees }\end{array}$ & $\begin{array}{c}\text { Capacitation } \\
\text { level }\end{array}$ \\
\hline $25-40$ years & 9 & 1 & $\begin{array}{c}\text { Ranged from } \\
\text { months to } 16 \text { years } \\
\text { of formation }\end{array}$ & $\begin{array}{c}\text { Nurse specialists in Family } \\
\text { Health; Medical-Surgical } \\
\text { Clinic and MSc. }\end{array}$ \\
\end{tabular}


tives and speech of the study subjects: Category 1-Nursing activities in patients with breast cancer; Category 2-Difficulties and facilities of taking care of these patients; Category 3-Technical care to be provided to patients; Category 4-How does the professional evaluate nursing actions regarding the support that the patient needs to face cancer and their possible consequences.

\section{Category 1-Nursing activities in patients with breast cancer}

Cancer still is understood by people, in general, as synonymous with pain, death and suffering. In this perspective, nurses must identify their own conceptions related to cancer and establish coping strategies, supported by COFEN 358/2009, 210/1998 and 211/1998 resolutions, thus aiming at an appropriate, humane and effective assistance that enables minimizing the suffering of all people involved [6].

In this context, to provide a satisfactory and effective nursing care, it is necessary for the nurse, as a member of the multidisciplinary team, to consider all these aspects in health care of this clientele, which will require, among other things, skills in interpersonal techniques, communication and therapeutic relationship [7].

Thus, it was evidenced that nurses realize that emotional support, nursing consultation, reception and assistance in coping, improve building a good performance of the professional nurse, as illustrated by the reports below:

"Nurses should help fighting the disease, exploring their feelings and life expectancies." (Enf 1 )

"Attention, I think this is the main tool of a nurse [...]"(Enf 2)

"We must be humanized, emphasizing aspects such as social, psychological [...]" (Enf4)

"The emotional support must permeate in all procedures and nursing queries [...]" (Enf 8)

"Nursing should welcome and establish a qualified hearing, aiming to identify possible repercussions through the nursing process [...]" (Enf 10)

In this sense, it is clear that the emotional support to these patients is as important as the care support, but there are still some professionals who prioritize only technical support, as shown in some reports:

"[ ... ] psychologist offers more professional support, it is not the reality of the nurse caring for the mental state of these patients. (Enf 7$)$ "

Thus, it highlights the importance of providing comprehensive care to the woman facing the related prejudice to the disease and who covers several steps from diagnosis to the confirmation of the disease, treatment and later stage treatment constituting moments of challenges to be overcome [8].

\section{Category 2-Difficulties and facilities of taking care of these patients}

When a woman finds breast cancer, she lives a very painful process and therefore the way the diagnosis will be transmitted to her will determine how the disease process will be faced [8].

Thus, the publication of Guidelines for the Early Detection of Breast Cancer in Bra- 
zil, launched in 2015 by the National Cancer Institute José Alencar Gomes da Silva (INCA) and the Ministry of Health, recommends that women and health professionals are informed about the importance of recognizing the signs and symptoms of breast cancer and the importance of quick and easy access to health services [3].

The long waiting time for carrying out the diagnostic tests and early treatment can have serious consequences for patients, such as the reduction of their chances of cure and survival time. In addition, a treatment performed later harms the quality of life; it requires more aggressive approaches, the need for use of multiple therapeutic approaches and results in the superposition of sequels. It is important to consider the increase of public expenditure as a result of more expensive and prolonged treatments, as well as social security costs arising from the removal of the work [9].

In this context, we see the need for information and assistance by qualified multidisciplinary team to these patients and even their families. However, nursing as a profession of caring, works more closely with the customer. We seek then to know the main difficulties and facilities by nurses in developed assistance to women with breast cancer. Thus, we have identified as major complaint about the denial of the patient to start treatment and lack of necessary and appropriate resources for assistance.

"The main difficulty is acceptance of the patient about the disease [... ]" (Enf 8)

"Lack of technical and hospital supplies for treatment." (Enf 2)

"The psychological aspect of the patient with breast cancer decreases adherence to treatment." (En 5)

"Lack of resources and help from the health department." (Enf4)

At this level of attention, there is the first assessment of women in RAS, being essential that teams are trained to recognize the needs of women throughout their life cycle (completeness). Specifically on the health of the breasts, the teams must be prepared to address both aspects of the trace of the cancer, according to the guidelines of the Ministry of Health, as complaints perceived by women. In any of the dimensions addressed, teams of basic attention should have dominion over built flows (regulation, reference and counter reference) to the levels of attention from medium and high complexity [3].

This implies the need for better resources to patient care as a measure of health education action by professionals, and to promote this form of prevention, resources are necessary for the entire population.

However, in order to easily, there is the intimacy that the nurse can exercise with the patient, as shown in the reports:

"It is easy to deal with this public when they are accessible and search the unit, creating a bond with the nurse [ ... ]" (Enf 1$)$.

"Therapeutic relationship through trust bond with the patient."(Enf2).

"Professional link with patient generates easy access to unit team [... ]" (Enf 7).

Insertion of the nursing staff in the care of the cancer patient requires knowledge, skills and responsibilities. In this sense, the goals must be clear and directed to the patient, her family and other significant people, covering aspects such as physical, emo- 
tional, social and spiritual [6].

Category 3-Technical care that should be provided to patients

In Brazil, the diagnosis of breast cancer is still done, most of the time, when the disease is in an advanced stage and the most used therapeutic conduct has been the radical surgical treatment, represented by mastectomy, which demands a lot of care focused on physical, emotional and social recovery of women facing this process [10].

When there is a surgical process, the woman should receive information about the care after surgery, guidelines and information about the various stages of recovery, how the surgery will be performed, care of the ipsilateral arm, exercises to recover the functional capacity of the arm and shoulder, as well as information about other treatments such as chemotherapy, radiation therapy and hormone therapy [11].

According to the understanding, we tried to know what are the technical, practical and theoretical care that should be provided by the nurse to these patients. It highlighted the care through dialogue, health education, as shown by the reports below:

"Stimulating the self-knowledge, encouraging the fight against cancer and treatments [...]" (Enf 10)

"Welcome, offer qualified listening, recognition of self-care changes, self-esteem

$[\ldots] "($ Enf 2$)$

"Promotion of self-care, clarification about the disease and treatment, pain relief and emotional support." (Enf8)

However, some nursing professionals prioritize specific care for the patient, leaving aside the bond and emotional support to the client, as illustrated in the reports below:

"When I find a lump in the breast during examination to prevent breast cancer, I forward the patient to the doctor. [...] If cancer is confirmed, the patient should be accompanied by a team of specific professionals." (Enf 1 )

The cancer care does not differ from assistance in other areas, being applied from the primary, secondary, tertiary care attention to the postmortem. The nurse's primary and secondary care has the responsibility to apply in his/her care area the knowledge of risk factors for breast cancer, disease prevention measures, through mammography and breast self-examination. Provide advice on the signs and warning signs for cancer, which perceived quickly lead to an early diagnosis and a favorable prognosis healing. In addition, it operates in the preoperative period of patients who undergo mastectomy, whether conservative or not. But the nurse of tertiary care seeks to meet the needs of patients who undergo additional treatment such as chemo prevention, radiation and hormone therapy [6].

Category 4-How to evaluate the performance of the professional nurse in relation to the support that the patient needs to receive to cope with cancer and its possible consequences

The diagnosis of cancer generally has a devastating effect on a person's life, either for fear of mutilation and disfigurement that treatments can cause, either by fear of death or many losses, in the emotional, social, and material areas, which almost always occur. 
Therefore, the attention to the emotional impact caused by the disease is essential in cancer patient care [7].

According to the above, it is possible to realize the importance of emotional support to those patients with breast cancer. However, we tried to find out how nurses evaluate the performance of nursing for the support that the patient needs to receive to cope with cancer and its possible consequences. We realized that the nurse is aware of the great importance of his/her role in the support to the patient, as shown in the reports below.

"Care is intrinsic to the profession of nurse; I see the humanization of the assistance in most nursing professionals." (Enf 10)

"The nurse has a fundamental role in the emotional support and clarification about the treatment of the disease." (Enf 8 )

"I think it is primordial and essential the presence of nurses in the care of these patients, since he/she has the role to clarify the disease, listening to the patient and encouraging treatment $[. .$.$] " (Enf 9$ )

Breast cancer is associated with a mental image related to pain, loss of libido, impotence, rejection and it could take these women to psychological misfits, manifested by feelings derived from the mutilation of the body, with direct reflections on sexual life that hinder interpersonal relationships. It affects, so intensively, the self-esteem of women, because the loss of a body part as breast reflects negatively on female identity maintenance [12].

Thus, it is important for nurses to know the experience of women in the discovery of this diagnosis, so he/she can provide adequate support and assist in addressing this situation, solving the doubts and concerns that may appear in this context [8].

\section{Final Considerations}

This research analyzed the importance of the role of nursing staff to patients living with breast cancer. Nurses interviewed were positioned according to the difficulties of operation of each area of work, but always facing the same problem: lack of resources for carrying support to breast cancer patients and weaknesses of these women to accept the disease as a result of denial of treatment.

In this context, it noticed the improvement of professional assistance as emotional support, pointing out that in most cases, nurses work with host, qualified listening, health education measures leading to self-knowledge, self-esteem and acceptance of the disease, and so creating bonds with the patients.

\section{References}

[1] Carvalho, S.M.F., Bezerra, I.M.P., Freitas, T.H., Rodrigues, R.C.S., Carvalho, I.O.C., Brasil, A.Q., Júnior, F.T.C., Diniz, F.L.B., Paz-Cox, A. and Abreu, L.C. (2015) Prevalence of Major Depression in Patients with Breast Cancer. Journal of Human Growth and Development, 25, 68-74. https://doi.org/10.7322/jhgd.96770

[2] INCA (2013) Controle do Câncer de Mama. Instituto Nacional do Câncer, Brasil. 
[3] INCA (2015) Monitoramento das ações de controle do câncer de mama linha de cuidado e rede de atenção ao câncer de mama. Instituto Nacional do Câncer, Brasil.

[4] Santana, V.S. and Peres, R.S. (2013) Perdas e ganhos: Compreendendo as repercussões psicológicas do tratamento do câncer de mama. Aletheia, 40, 31-42.

[5] Costa, W.B., Vieira, M.R.M., Nascimento, W.D.M., Pereira, L.B. and Leite, M.T.S. (2012) Mulheres com câncer de mama: Interações e percepções sobre o cuidado do enfermeiro. Revista Mineira de Enfermagem, 16, 31-37.

[6] Mineo, F.L.V., Mattos, L.F.B. and Lima, S.S. (2013) Assistência de enfermagem no tratamento do câncer de mama. Revista Eletrônica Gestão \& Saúde, 4, 2238-2260.

[7] Silva, L.C. (2008) Câncer de mama e sofrimento psicológico: Aspectos relacionados ao feminino. Psicologia em Estudo, 13, 231-237.

https://doi.org/10.1590/S1413-73722008000200005

[8] Paiva, A.C.P.C. and Salimena, A.M.O. (2016) O olhar da mulher sobre os cuidados de enfermagem ao vivenciar o câncer de mama. HU Revista, Juiz de Fora, 42, 11-17.

[9] Paiva, C.J.K. and Cesse, E.A.P. (2015) Aspectos Relacionados ao Atraso no Diagnóstico e Tratamento do Câncer de Mama em uma Unidade Hospitalar de Pernambuco. Revista Brasileira de Cancerologia, 61, 23-30.

[10] Alvez, P.C., Barbosa, I.C.F.J., Caetano, J.A. and Fernandes, A.F.C. (2011) Cuidados de enfermagem no pré-operatório e reabilitação de mastectomia: Revisão narrativa da literatura. Revista Brasileira de Enfermagem, 64, 732-737. https://doi.org/10.1590/S0034-71672011000400016

[11] Barreto, R.A.S., Suzuki, K., Lima, M.A. and Moreira, A.A. (2008) As necessidades de informação de mulheres mastectomizadas subsidiando a assistência de enfermagem. Revista Eletrônica de Enfermagem, 10, 110-123.

[12] Salimena, A.M.O., Campo, T.S., Melo, M.C.S.C. and Magacho, E.J.C. (2012) Mulheres enfrentando o câncer de mama. Revista Mineira de Enfermagem, 16, 339-347.

\section{Submit or recommend next manuscript to SCIRP and we will provide best service} for you:

Accepting pre-submission inquiries through Email, Facebook, LinkedIn, Twitter, etc. A wide selection of journals (inclusive of 9 subjects, more than 200 journals)

Providing 24-hour high-quality service

User-friendly online submission system

Fair and swift peer-review system

Efficient typesetting and proofreading procedure

Display of the result of downloads and visits, as well as the number of cited articles Maximum dissemination of your research work

Submit your manuscript at: http://papersubmission.scirp.org/

Or contact ojn@scirp.org 